\title{
Climate hazards are threatening vulnerable migrants in Indian megacities
}

In recent decades, India has witnessed a rapid pace of migration from areas with intensive agriculture to populated megacities, which are faced with increasing threat from climate hazards. Greater attention is needed for vulnerable new migrants who lack necessary resources when designing adaptation and mitigation policies.

\section{Vittal Hari, Suman Dharmasthala, Akash Koppa, Subhankar Karmakar and Rohini Kumar}

R educing the impact of human-induced climate change through mitigation and adaptation is one of the most important challenges of our time, especially for vulnerable developing countries ${ }^{1}$. Among these, large-scale population displacements, historically driven by socioeconomic factors and increasingly exacerbated by climate change, is a pressing global issue ${ }^{2}$. In India, as per the 2011 Census, around 455 million people migrated, of which $64 \%$ were from the rural areas ${ }^{3}$. A large majority of the migrants are from the low-income states of Uttar Pradesh and Bihar (36\% of the total out of state migration) - these northern states belong to South Asia's most intensively cropped Indo-Gangetic (IG) region ${ }^{4}$ (Fig. 1). This out-migration is both seasonal and permanent in nature, mainly undertaken by the marginalized population who primarily depend on agriculture ${ }^{3,5}$, revealing a systemic instability, or 'risk', in the sector. The IG region is also India's most densely populated area, where approximately 640 million people live in poverty ${ }^{4}$. The pace of migration from these regions has intensified during the recent decade (Fig. 1) - a trend that is likely to continue in future ${ }^{6}$.

Rising temperature adversely impacts the agriculture, thereby increasing the vulnerability ${ }^{7,8}$ of marginalized agriculture-dependent rural populations. Thus, climate change can be a catalyst for such migrants to relocate in search of better living conditions and alternate livelihoods 9 . Although migration is perceived as an important adaptation mechanism to counteract the negative outcomes of climate change ${ }^{2}$, climate extremes at the destination location, on the other hand, can have a detrimental effect on these migrants ${ }^{10}$, as population dynamics and climate change is considered a mutually interacting two-way avenue ${ }^{2}$. Therefore, an improved and systematic understanding of climate change-induced risks that the migrants face at the destinations, especially in megacities, is of utmost importance.

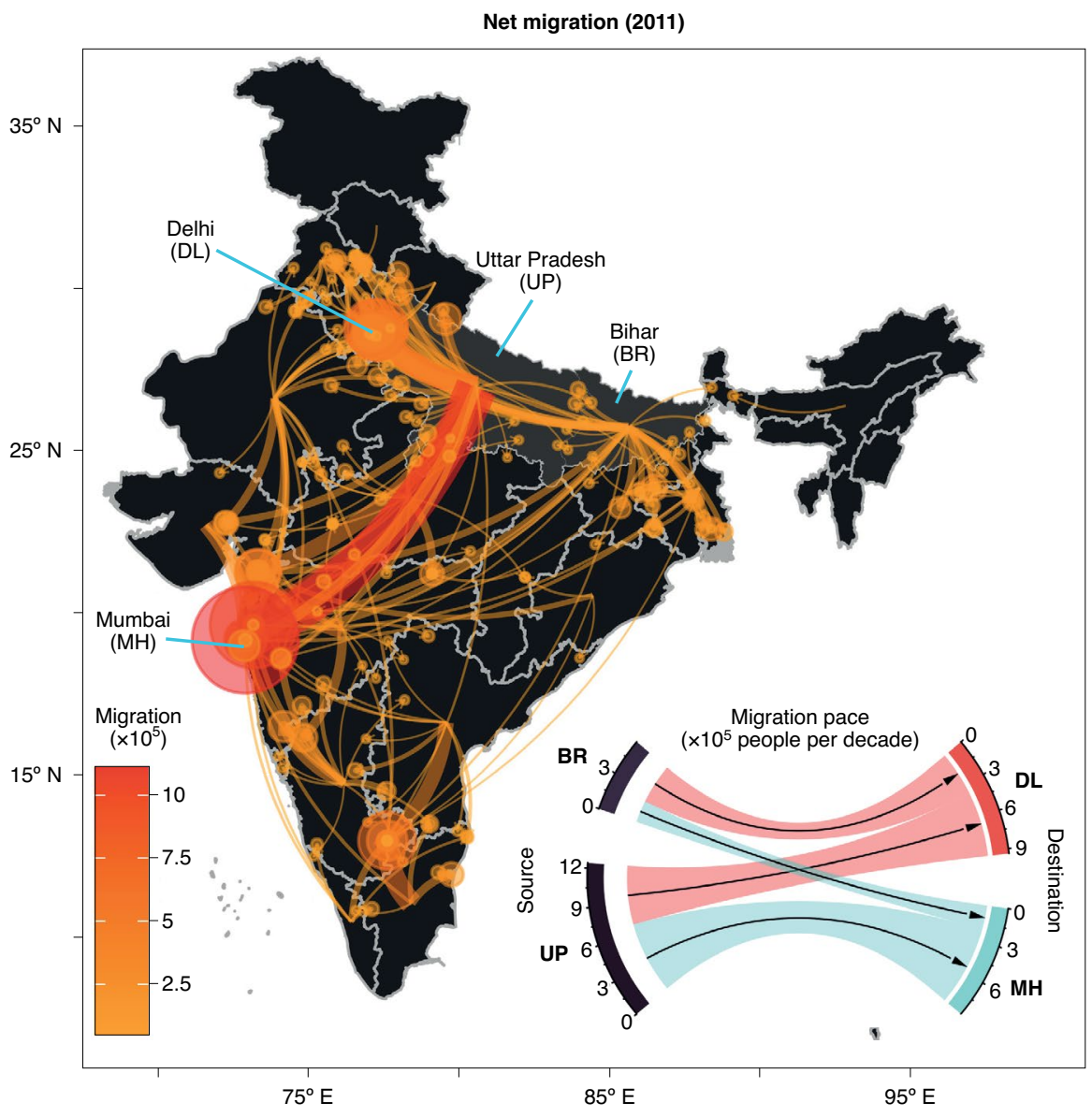

Fig. 1 | Pattern of flow of inter-state migration based on the $\mathbf{2 0 1 1}$ India Census. For lucidity, the migration volume greater than 50,000 people is shown, and the migrant destinations are accordingly sized based on the in-migration volume. The pace of migration between the decades 2001 and 2011 for two major sources (Uttar Pradesh (UP) and Bihar (BR)) and destinations (Maharashtra (MH) and Delhi $(D L))$ is provided in the inset.

Challenges at migrant destinations While migrating to mega cities makes sense from a socioeconomic perspective, it is important to acknowledge that major migrant destinations - specifically the megacities, like Mumbai and Delhi — are witnessing a substantial increase in multiple climate-related threats. Here, we highlight how the emergence of two fundamentally different but equally devastating hazards - heatwaves and floods - can contribute to the vulnerability of migrants at their destination. In South Asia, deadly heatwaves are projected to increase in the future ${ }^{11}$, 
thus posing a serious threat to public health. As increasing heat in urban areas is intrinsically linked to population growth ${ }^{12}$, we envisage that a large influx of migrants will further amplify the effect of heatwaves in the already densely populated megacities. For example, Delhi has witnessed record summer temperatures for several years in a row, accompanied by higher fatalities and hospitalization ${ }^{13}$. More importantly, the most adverse effects of these heatwaves will likely be felt more by the migrant community, as they already live in closely packed, sub-optimal dwellings, and any mitigating resource, such as appropriate housing or air conditioning, is beyond their reach.

Another major hazard is flooding in coastal cities such as Mumbai caused by tropical cyclones and sea-level rise. A substantial rise in the pre-monsoon sea-surface temperature trends across the Northern Indian Ocean, specifically in the Arabian Sea, creates a conducive environment for the genesis and propagation of tropical cyclones ${ }^{14}$. This situation, further aggravated by the swift increase in the mean sea level ${ }^{15}$, would increase the risk of coastal flooding. Moreover, flooding in the coastal cities would likely pose major difficulties ${ }^{16}$ for both short-term emergency management and the longer-term recovery of these marginal communities, who generally live in low-elevation areas ${ }^{16}$. Due to this, the coastal cities - specifically Mumbai, where the influx of marginal migrants is very high - face immense challenges in managing the increasing hydroclimatic hazards, the consequences of which are experienced by the large vulnerable population and are often met with huge monetary losses ${ }^{17}$.

These climate-related hazards paint an alarming scenario in which the major migrant destinations will emerge as hotspots of climate-induced disruptions, wherein vulnerable migrants are expected to be the most impacted. The lack of basic resources - such as proper shelter, healthcare and clean drinking water - for these segments of population may therefore make them more susceptible to higher health risks ${ }^{17}$. Overall, there is a pressing need for robust policy frameworks to protect these marginal migrants from contemporary and future climatic hazards.

\section{Strategies for migrant communities}

While adaptation measures had generally taken a backseat to mitigation efforts in the fight against climate change ${ }^{18}$, in India, there is an emerging cognizance of the need to simultaneously undertake mitigation and adaptation efforts, as outlined in its National Action Plan for Climate Change ${ }^{19}$. India has evolved from a 'growth-first' stance to a more 'climate responsible and mitigating' stance in its policies ${ }^{20}$. This change in the national policy outlook has trickled down to the State Action Plans as well ${ }^{21}$. Various strategies are being implemented in the agricultural sector to curtail the adverse impacts of climate change, including credits for crops, better and adaptive water and crop management (for example, stress-tolerant varieties, crop rotation) and climate-smart (resilient) measures ${ }^{22}$. Such measures are especially necessary given that the overall risk in agriculture sector has risen over the past decades owing to increased climatic hazards ${ }^{7,8,23}$, and the trend is likely to continue in the future. These conditions generally act as a catalyst for the contemporary and future migration of marginal communities from agriculture-intensive areas to megacities ${ }^{6}$. Even though such strategies are in place at the source of migration, policies targeting the vulnerable migrants at the destinations are severely lacking.

Cities - specifically in the global south - despite having increased footprint of carbon emissions, have enormous potential for transformational adaptation ${ }^{24}$. In India, many cities have endorsed climate adaptation actions ${ }^{25}$ - for example, Ahmedabad, a city prone to intense heatwaves, has evolved a comprehensive Heat Action Plan ${ }^{26}$. Mumbai, on the other hand, where the influx of migrants is more pronounced, faces myriad climate-related challenges and lacks the requisite sectoralor city-level adaptation policies ${ }^{25}$. While there are a few government schemes that exist to reduce the vulnerability of these migrants, some only exist in the state of their domicile and are not easily portable to the states of destination. Social-security-related initiatives of the government, such as the unique identification number ('Aadhaar' in India), enable availing of certain services such as insurance, pensions and bank accounts, irrespective of the domicile. The most recent such effort has been that of the portability of ration cards across the country ${ }^{27}$. However, services which are important for the subsistence of the migrants, such as healthcare and housing, are generally not accessible at destinations. In addition, the lack of access to education, which is hindered by language barriers, and lack of housing due to limited and/or unaffordable housing supply in megacities ${ }^{28}$, exemplifies the existing vulnerability of migrants to a large extent. The marginal migrants - who usually have the fewest resources to protect against external disturbances - are among the worst hit by these impacts.
External shocks usually have detrimental effects on the coping capacities of marginal migrants. This was, for example, starkly evident during India's COVID-19 lockdown in 2020 - the reverse migration of around 40 million marginal migrants from urban areas back to their respective places of origin, in a span of few days ${ }^{29}$, highlights the vulnerability of migrants in the face of an external adversity. Such increased vulnerability of socioeconomically disadvantaged migrants from rural areas is a common concern for not only India, but also other developing countries experiencing both climate threat and rapid urbanization. Therefore, concerted efforts should be devoted towards capacity building and adaptation actions to not only accommodate these migrants in the megacities, but also ensure that they can withstand the vagaries of climate-related hazards. While devising policies for climate mitigation and adaptation, special focus is needed for attenuating the vulnerability of the marginal migrants in megacities and other major destinations.

\section{Vittal Hari Did ${ }^{1,6 凶}$, Suman Dharmasthala ${ }^{2,6}$, Akash Koppa ${ }^{3}$, Subhankar Karmakar ${ }^{4,5}$ and Rohini Kumar (D) 1 ه}

${ }^{1}$ UFZ-Helmholtz Centre for Environmental Research, Leipzig, Germany. ${ }^{2}$ Faculty of Environmental Sciences, Czech University of Life Sciences Prague, Prague, Czech Republic. ${ }^{3}$ Hydro-Climate Extremes Lab (H-CEL), Faculty of Bioscience Engineering, Ghent University, Ghent, Belgium. ${ }^{4}$ Environmental Science and Engineering Department, Indian Institute of Technology Bombay, Mumbai, India. ${ }^{5}$ Interdisciplinary Program (IDP) in Climate Studies, Indian Institute of Technology, Mumbai, India. ${ }^{6}$ These authors contributed equally: Vittal Hari, Suman Dharmasthala.

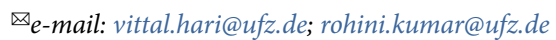

Published online: 19 July 2021

https://doi.org/10.1038/s41558-021-01105-7

References

1. Smith, M. R. \& Myers, S. S. Nat. Clim. Change 8, 834-839 (2018).

2. Marotzke, J., Semmann, D. \& Milinski, M. Nat. Clim. Change 10, 518-525 (2020).

3. Data on Migration 2011. Office of the Registrar General \& Census Commissioner, India https://censusindia.gov.in/2011census/ migration.html (2011).

4. Lopez-Ridaura, S. et al. Agric. Syst. 159, 57-68 (2018).

5. Keshri, K. \& Bhagat, R. B. Asian Popul. Stud. 9 , 175-195 (2013).

6. FAO Migration Framework - Migration as a Choice and an Opportunity for Rural Development (FAO, 2019).

7. Sharma, T., Vittal, H., Karmakar, S. \& Ghosh, S. Environ. Res. Lett. 15, $034010(2020)$.

8. Vittal, H., Karmakar, S., Ghosh, S. \& Murtugudde, R. Environ. Res. Lett. 15, 014005 (2020).

9. Black, R., Bennett, S. R., Thomas, S. M. \& Beddington, J. R. Nature 478, 447-449 (2011).

10. Panda, A. Econ. Polit. Wkly 14, 20 (2010).

11. Saeed, F., Schleussner, C.-F. \& Ashfaq, M. Geophys. Res. Lett. 48 , e2020GL091191 (2021)

12. Manoli, G. et al. Nature 573, 55-60 (2019). 
13. Murari, K. K., Ghosh, S., Patwardhan, A., Daly, E. \& Salvi, K. Reg. Environ. Change 15, 569-579 (2015)

14. Murakami, H., Vecchi, G. A. \& Underwood, S. Nat. Clim. Change 7, 885-889 (2017)

15. Hallegatte, S. et al. Flood Risks, Climate Change Impacts and Adaptation Benefits in Mumbai: An Initial Assessment of Socio-Economic Consequences of Present and Climate Change Induced Flood Risks and of Possible Adaptation Options OECD Environment Working Papers, No. 27 (OECD, 2010).

16. Prandi, P. et al. Sci. Data 8, 1 (2021).

17. Mazdiyasni, O. \& AghaKouchak, A. GeoHealth 4 e2019GH000219 (2020)

18. Khan, M. R. \& Roberts, J. T. Wiley Interdiscip. Rev. Clim. Change 4, 171-189 (2013)

19. National Action Plan on Climate Change. Ministry of Environment, Forest and Climate Change, Government of India http://moef govin/division/environment-divisions/climate-changecc-2/ national-action-plan-on-climate-change/ (2021).

20. Mohan, A. Rising Powers Quarterly 2, 39-60 (2017).

21. State Action Plan on Climate Change. Ministry of Environment, Forest and Climate Change, Government of India http://moef. gov.in/division/environment-divisions/climate-changecc-2 state-action-plan-on-climate-change/ (2021).

22. Amjath-Babu, T. S., Aggarwal, P. K. \& Vermeulen, S. Clim. Policy 19, 283-298 (2019).
23. Lobell, D. B., Schlenker, W. \& Costa-Roberts, J. Science 333 616-620 (2011)

24. IPCC Climate Change 2014: Impacts, Adaptation, and Vulnerability (eds Field, C. B. et al.) 535-612 (Cambridge Univ. Press, 2014).

25. Singh, C., Madhavan, M., Arvind, J. \& Bazaz, A. Urban Clim. 36, 100783 (2021)

26. Ahmedabad Heat Action Plan (Ahmedabad Municipal Corporation, 2018); https://www.nrdc.org/sites/default/files/ ahmedabad-heat-action-plan-2018.pdf

27. Implementation of ONORC scheme. Ministry of Consumer Affairs, Food \& Public Distribution https://pib.gov.in PressReleaselframePage.aspx?PRID=1694556 (2021).

28. Report of the Working Group on Migration (Ministry of Housing and Poverty Alleviation, 2017); http://mohua.gov.in/upload/ uploadfiles/files/1566.pdf

29. COVID-19 Crisis Through a Migration Lens (World Bank Group, 2020); http://documents.worldbank.org/curated/en/ 989721587512418006/COVID-19-Crisis-Through-aMigration-Lens

The authors acknowledge the efforts of Census of India (Government of India) for making the migration data publicly available. This work was partly carried out within the bilateral project XEROS (eXtreme EuRopean drOughtS: multimodel synthesis of past, present and future events), funded by the Deutsche Forschungsgemeinschaft (grant RA 3235/1-1) and Czech Science Foundation (grant 19-24089J). S.K. acknowledges the Department of Science \& Technology (SPLICE-Climate Change Programme) and the Government of India (project reference no. DST/ CCP/CoE/140/2018; grant no. 00000000000010013072 (UC ID: 18192442)). A.K. acknowledges support from the European Union Horizon 2020 program, project no. 869550 (DOWN2EARTH).

\section{Author contributions}

V.H. and S.D. conceptualized and designed the study together with R.K. and S.K. S.D. and V.H. conducted the analysis, with inputs from R.K. and A.K. S.D., V.H. and A.K. drafted the manuscript. All author contributed in editing and reviewing of the manuscript.

The authors declare no competing interests.

\section{Emissions estimations should embed a precautionary principle}

To align their portfolios with the Paris Agreement, investors need to know the emissions of companies they invest in. Estimating these should start from a precautionary principle that disincentivizes free-riding and protects the planet.

\section{Andreas G. F. Hoepner and Joeri Rogelj}

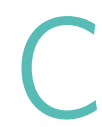
limate action is sprouting worldwide. Companies around the world are announcing greenhouse gas (GHG) emission reduction targets (for example, see ref. ${ }^{1}$ ), and the EU has now published Paris Aligned Benchmarks that require participating investors to reduce the average GHG emissions of the portfolio of companies in which they invest by $7 \%$ per year (weighted by their investment value; for example, see refs. $\left.{ }^{2-4}\right)$. Reliable targets and their achievement rely on robust GHG data. To calculate weighted average GHG emissions, investors need emissions data for any potentially investable company globally. This information is necessary regardless of whether the company (i) has a target, (ii) is reporting company-wide GHG emissions or (iii) is participating partly or in whole in the EU's Emissions Trading Scheme (ETS; where emissions of participating facilities are verified). Hence, many investors are now starting to assess available GHG emissions data to understand their position and plan a strategy ahead. This includes (i) detailed milestone data on pathways that meet the climate goals of the Paris Agreement ${ }^{5,6}$ and estimates of actors' (ii) past and (iii) present GHG emissions ${ }^{7,8}$. Notably, GHG emissions reported by organizations are always estimates, as no organization has the capacity to install sufficient sensors to literally measure $100 \%$ of their GHG emissions ${ }^{9}$. With this demand for data of sufficient quality that is needed for making investment decisions also comes an important responsibility: investors and their delegates (for example, rating agencies) who collect and estimate GHG emissions data, or scientists supporting them, should take into account the incentives that come with the estimates they provide. Specifically, methods for providing climate and other environmental information for target setting should be impregnated with the precautionary principle.

\section{Problem for investors}

Wherein lies the problem for investors? Underreporting or non-reporting of GHG emissions is a prevalent and systematic global problem. While the EU ETS has introduced a system of regulated GHG emissions verification for about half of
Europe's emissions, and China's ETS launched earlier this year aims to have similar features, investors need GHG emissions data for companies globally. All relevant global environmental initiatives, however, such as Carbon Disclosure Project (CDP; founded in 2000; https://www. cdp.net/en), Greenhouse Gas Protocol (launched in 2001; https://ghgprotocol. org/) or Sustainability Accounting Standards Board (SASB; launched in 2011; https:// www.sasb.org/) rely on organizations voluntarily self-reporting forms of pollution, be it GHG emissions, air pollution, water or other environmental indicators. Many organizations, especially those that have commercial for-profit motives, have a strong incentive to represent themselves as being as green as possible when participating in these self-reporting initiatives ${ }^{10}$. Investors, however, need GHG emissions data for any investable company globally. In the absence of better alternatives outside EU ETS coverage, they use self-reported information and thereby suffer from either underrreporting or non-reporting of GHGs. The severity of the challenge can 